\title{
Properties of gypsum composites containing vermiculite and polypropylene fibers: Numerical and experimental results
}

\author{
Osman Gencel ${ }^{\mathrm{a}, *}$, Juan Jose del Coz Diaz ${ }^{\mathrm{b}}$, Mucahit Sutcu $^{\mathrm{c}}$, Fuat Koksal ${ }^{\mathrm{d}}$, \\ F.P. Alvarez Rabanal ${ }^{\mathrm{b}}$, Gonzalo Martinez-Barrera ${ }^{\mathrm{e}}$, Witold Brostow ${ }^{\mathrm{f}, 1}$ \\ a Civil Engineering Department, Faculty of Engineering, Bartin University, 74100 Bartin, Turkey \\ ${ }^{\mathrm{b}}$ Department of Construction, University of Oviedo, 33204 Gijón, Spain \\ c Department of Materials Science and Engineering, Faculty of Engineering and Architecture, Izmir Kâtip Celebi University, 35620 Izmir, Turkey \\ d Department of Civil Engineering, Bozok University, 66000 Yozgat, Turkey \\ e Laboratorio de Investigación y Desarrollo de Materiales Avanzados (LIDMA), Facultad de Química, Universidad Autónoma del Estado de México, \\ Km.12 de la carretera Toluca-Atlacomulco, San Cayetano 50200, Mexico \\ ${ }^{\mathrm{f}}$ Laboratory of Advanced Polymers and Optimized Materials (LAPOM), Department of Materials Science and Engineering and Center for Advanced Research \\ and Technology (CART), University of North Texas, 3940 North Elm Street, Denton, TX 76207, USA
}

\section{A R T I C L E I N F O}

\section{Article history:}

Received 31 May 2013

Received in revised form 7 November 2013

Accepted 13 November 2013

\section{Keywords:}

Gypsum composite

Vermiculite

Polypropylene fibers

Thermal conductivity

Mechanical strength

Response surface methodology

Finite element modeling

\begin{abstract}
A B S T R A C T
We have added expanded vermiculite and polypropylene fibers with low thermal conductivity to lightweight gypsum. Thermal conductivity of the composites decreases on addition of vermiculite as pore-maker. Physical and mechanical properties of the composites are improved by incorporating polypropylene fibers. A nonlinear finite element model of a three point bending model and a design of experiments analysis have been developed to evaluate and optimize the additive concentrations and also to understand the effects provided by the additives on the mechanical strength. Statistical response surface method with three-level factorial was employed to evaluate the effect of addition of vermiculite and polypropylene fibers on gypsum composites. Our methodology can be applied to other nonlinear materials for property optimization.
\end{abstract}

(c) 2013 Elsevier B.V. All rights reserved.

\section{Introduction}

Gypsum plaster and board along with composites based on them have been increasingly used in building construction [1-14]. Thermal and sound-proofing properties of the gypsum building materials can be improved by increasing the porosity, e.g. by foaming [5] or by adding pore-forming agents such as inorganic ones [6-8]. Different clay minerals can be added to gypsum plaster in order to modify the physical properties [6]. Physical and thermal conductivity properties were improved by the addition of expanded silica gel granules introduced into the gypsum [8]. Also, reinforcing materials such as fibers or aggregates with different sizes are added to the gypsum plaster and board to improve certain mechanical properties [1,2,15-17]. Several different types of polymeric fibers such as glass fiber, carbon fiber, polypropylene

\footnotetext{
* Corresponding author. Tel.: +90 378223 5360; fax: +90 3782235258

E-mail address: osmangencel@gmail.com (O. Gencel).

URL: http://www.unt.edu/LAPOM (W. Brostow)

1 Tel.: +1 940565 4358; fax: +1 9405654824 .
}

fiber, polyamide fiber, polyester fiber have been extensively used in gypsum boards for their specific advantages [1-5,18-20]. The use of fiber reinforcement materials in gypsum mix allows increasing the materials strength. Existing studies use different fiber type, while no results have been reported for using both vermiculite and polymeric fibers.

The expanded vermiculite used by us as a mineral additive to obtain a low thermal conductivity is one of the natural clay minerals that have phyllosilicate groups $\left[(\mathrm{Mg}, \mathrm{Fe}, \mathrm{Al})_{3}(\mathrm{Al}\right.$, $\mathrm{Si})_{4} \mathrm{O}_{10}(\mathrm{OH})_{2} \cdot 4 \mathrm{H}_{2} \mathrm{O}$ ] composed of shiny flakes, resembling mica in appearance. When vermiculite is heated to elevated temperatures, its flakes expand as much as 8-30 times with respect to their original size due to the removal of their interlayer and structural water. Expanded vermiculite has a very low density and low thermal conductivity, high fire resistance and strong sound absorption, what makes it attractive for use as a lightweight construction aggregate, thermal insulation filler and soil modifier. Due to its lower density, such vermiculite is used as a constituent of concretes and plasters $[9,21]$. The use of expanded vermiculite in gypsum mix should allow a reduction of the density and thermal conductivity values of the gypsum composites. 
Polypropylene (PP) fibers were added to the gypsum composite mixtures to improve the mechanical properties. According to Tazawa [19], the local response of fiber/matrix interface during fracture is of great importance. The most important effect of fibers is to act as bridging ligaments in the crack plane in order to limit crack propagation and opening, increasing the deformation energy needed to reach fracture. However, the stress transfer between matrix and fibers is complicated and models dealing with effects of the different fiber ratios on the mechanical properties of gypsumreinforced composite were not available.

Numerical studies of laboratory results have become a useful tool for both engineers and researchers, as shown by the ever-growing number of books and articles published and the conferences dedicated to this subject. Much can be learned from the engineering of Simulation and Testing (or Hybrid Engineering) that can later be applied to improvements in the field of structural and thermal design and analysis in the form of new theories, concepts or details [18,22-25].

Along these lines, there are models dealing with analytical modeling of strength in fiber reinforced gypsum composites [18], the effect of self-stress on flexural resistance [19], the effect of longitudinal reinforcement on glass fiber reinforced gypsum [20]. However, most of the studies related to gypsum composites have concentrated on analytical or laboratory tests and very few pay attention to numerical models based on the finite element modeling (FEM) and the design of experiments (DOE) methodology play [26-28].

We have prepared lightweight gypsum composites containing expanded vermiculite and polypropylene fibers to examine their thermal conductivities and physical and mechanical properties. In order to understand the effect on mechanical resistance of vermiculite and polypropylene fibers, a nonlinear three point bending FEM analysis is performed. The structural nonlinearity is due to the possibility of cracking and crushing.

With the basis in this nonlinear structural numerical model, a search for optimal value based on the designs of experiments (DOE) $[19,20,28,29]$ and goal optimization analysis have been performed to define the optimized fiber concentration [30,31].

\section{Experimental studies}

\subsection{Gypsum}

A commercially available gypsum plaster mix characterized according to TS EN 13279-1 [32] was used in this study. The properties of gypsum used were given in Table 1.

\subsection{Vermiculite}

Exfoliated vermiculite was supplied from the Demircilik vermiculite deposit in Yıldızeli, Sivas, Turkey. The vermiculite was obtained by heating raw vermiculite at $600^{\circ} \mathrm{C}$ for $10 \mathrm{~s}$. Then the vermiculite was ground and fine sized particles smaller than sieving intervals of 100 -mesh $(149 \mu \mathrm{m})$ were used for plaster mixes. The chemical and physical properties of exfoliated vermiculite are

Table 1

The properties of gypsum used.

\begin{tabular}{ll}
\hline Workability time (min) & $60-90$ \\
Final setting time (min) & 150 \\
Compressive strength (MPa) & 2.5 \\
Flexural strength (MPa) & 1 \\
Dry density $\left(\mathrm{kg} / \mathrm{m}^{3}\right)$ & $650-1000$ \\
$1000 \mu \mathrm{m}(\%$ passing) & 100 \\
$150 \mu \mathrm{m}(\%$ passing) & 60 \\
Chemical formulation & $\mathrm{CaSO}_{4} \cdot 1 / 2 \mathrm{H}_{2} \mathrm{O}$ \\
\hline
\end{tabular}

Table 2

Properties of additives used for gypsum composites.

\begin{tabular}{|c|c|c|}
\hline & $\begin{array}{l}\text { Exfoliated } \\
\text { vermiculite }\end{array}$ & Polypropylene fiber \\
\hline \multicolumn{3}{|l|}{ Physical properties } \\
\hline Color & Silver & White \\
\hline Shape & $\begin{array}{l}\text { Accordion } \\
\text { shaped granule }\end{array}$ & - \\
\hline Water holding capacity & 240 wt.\% & - \\
\hline Cation exchange capacity & $90 \mathrm{meg} / 100 \mathrm{~g}$ & - \\
\hline $\mathrm{pH}$ (in water) & 6.1 & - \\
\hline Thermal conductivity $(\mathrm{W} / \mathrm{mK})$ & 0.063 & - \\
\hline Combustibility & $\begin{array}{l}\text { Non- } \\
\text { combustible }\end{array}$ & - \\
\hline Specific heat (kcal/kg K) & 0.22 & - \\
\hline Bulk density ( $\left.\mathrm{g} / \mathrm{cm}^{3}\right)$ & 0.140 & 0.91 \\
\hline Tensile strength $\left(\mathrm{N} / \mathrm{mm}^{2}\right)$ & - & $300-400$ \\
\hline Aspect ratio (L/D) & - & $545(12 \mathrm{~mm} / 0.022 \mathrm{~mm})$ \\
\hline \multicolumn{3}{|l|}{ Chemical composition (\%) } \\
\hline $\mathrm{SiO}_{2}$ & 34.1 & \\
\hline $\mathrm{Al}_{2} \mathrm{O}_{3}$ & 17.2 & \\
\hline $\mathrm{K}_{2} \mathrm{O}$ & 4.52 & \\
\hline $\mathrm{CaO}$ & 6.4 & \\
\hline $\mathrm{MgO}$ & 16.3 & \\
\hline $\mathrm{Fe}_{2} \mathrm{O}_{3}$ & 14.7 & \\
\hline Loss on ignition & 6.4 & \\
\hline
\end{tabular}

presented in Table 2. Exfoliated fine vermiculite was added to the plaster mixtures at ratios of $10 \mathrm{wt} . \%$ and $20 \mathrm{wt} . \%$. The amount of vermiculite listed is the ratio of the vermiculite mass to the total dry mass.

\subsection{Polypropylene fibers}

Polypropylene fibers with $22 \mu \mathrm{m}$ diameter and $12 \mathrm{~mm}$ length were used, their properties listed in Table 2 . The fibers were added to the mixtures in the ratios of $0.5 \mathrm{wt} . \%$ and $1.0 \mathrm{wt} . \%$. The amount of fibers is counted as a ratio to the total dry mass.

\subsection{Response surface method}

We have used a multi-objective simultaneous optimization technique to optimize gypsum composites, to which the response surface method (RSM) is incorporated. The RSM uses statistical techniques for empirical model building; it comprises regression surface fitting to obtain approximate responses, design of experiments to obtain minimum variances of the responses and optimizations using the approximated responses. The RSM also aims to reduce the cost and save time [33,34]. This approach has been widely used to optimize products and processes in manufacturing, chemical and other industries, but it has had very limited use in the construction industry. In one such study, Simon et al. [35] optimized high performance concrete mixtures. Bayramov et al. [36] optimized the fracture parameters of steel fiber reinforced concrete to obtain a more ductile behavior. Some of us [37] optimized abrasive wear of concrete.

In the experiments, the mixture ratios were defined by the use of a statistical experimental design technique. A RSM with threelevel factorial was employed to study the effect of two factors (vermiculite and polypropylene fiber) on samples of gypsum composites. Three response variables were measured: dry unit weight, compressive strength and thermal conductivity. This experimental design referred 13 experiments with four replicates in the center point. These factors were investigated at three levels; low $(-)$, medium $(0)$ and high $(+)$ level as shown in Table 3 . The Analysis of Variance (ANOVA) test for response surface quadratic model was used to determine the impact of independent variables on all dependent response variables in a regression analysis. 
Table 3

Parameters of response surface design with three-level factorial.

\begin{tabular}{lcl}
\hline Levels & A: vermiculite (wt.\%) & B: polypropylene (PP) fiber (wt.\%) \\
\hline Low $(-1)$ & 0 & 0 \\
Medium $(0)$ & 10 & 0.5 \\
High $(+1)$ & 20 & 1 \\
\hline
\end{tabular}

Mathematical equations in terms of coded factors for all responses were constructed. The response surface plots were constructed based on vermiculite and polypropylene fiber content.

One begins with experimental results. Analysis of response surface involves choosing a model that fits the experimental data and testing the adequacy of that model. A response surface is the diagram of system dependent variables or responses as a function of one or more independent variables or factors. The response surface allows a visual analysis of how certain factors influence the responses. After building a model, the optimization procedure is performed using the response surface of that model as the basis for finding the best solution. Without establishing a model, optimization does not lead to a general solution of the problem.

\subsection{Preparation of the gypsum composites}

Experimental set and mix proportions of the gypsum composite are presented in Table 4. The gypsum mixtures containing with vermiculite and PP fibers were prepared in a mixer. The gypsum and additives were first put in the mixer and mixed for 5 min in order to achieve a homogeneous dry mixture. Water was then added to the dry mixture and mixed for $3 \mathrm{~min}$ so as to obtain the plaster slurry. The ratio of plaster mix/water used was $900 \mathrm{~g} / 585 \mathrm{ml}$. The water used during these experiments was the room temperature of about $20^{\circ} \mathrm{C}$. Two different shaped molds with dimensions of $120 \mathrm{~mm} \times 120 \mathrm{~mm} \times 20 \mathrm{~mm}$ and $40 \mathrm{~mm} \times 40 \mathrm{~mm} \times 160 \mathrm{~mm}$ were prepared to produce test samples.

Rectangular $(40 \mathrm{~mm} \times 40 \mathrm{~mm} \times 160 \mathrm{~mm})$ and plate shape $(120 \mathrm{~mm} \times 120 \mathrm{~mm} \times 20 \mathrm{~mm})$ samples were formed by slurry casting for the mechanical tests and thermal conductivity determination, respectively. For each test, three series of specimens were produced. In the meantime, the slurry was compacted by a shaker for $10 \mathrm{~s}$ in order to ensure complete filling of the mold. All the specimens were kept in molds for $24 \mathrm{~h}$ at room temperature, and then removed from molds. The specimens were left to dry in ambient conditions for 28 days, further dried in an oven maintained at $40^{\circ} \mathrm{C}$ for $48 \mathrm{~h}$. Dry unit weight values of the samples were measured after drying steps. Then porosity and water absorption values, mechanical properties like compressive and bending strengths and thermal conductivity were determined.

\section{Experimental results}

Compressive and bending strengths, of the gypsum composite samples were measured following the TS EN 13279-2 standard [38]. The dry unit weight, porosity and water absorption values were determined by Archimedes method (soaking period of $24 \mathrm{~h}$ in water at room temperature). In order to determine the thermal conductivity of the samples a TCi Thermal Conductivity Analyzer has been used. This instrument has been developed by C-Therm Technologies and it is based on the Modified Transient Plane Source (MTPS) method, a non-destructive technique allowing us to obtain the thermal conductivity and effusivity of the samples tested $[39,40]$. Table 3 presents the results for all runs.

The mathematical models derived from the experimental results and their Analysis of Variance (ANOVA) test results are shown in Tables 5-7.
Response surface three-level factorial design was conducted to find main factors. The design refers to quadratic model with $R^{2}=0.78$ and the standard deviation of $0.02\left(R^{2}=1\right.$ represents the perfect fit). The ANOVA test results for the dry unit weight data are given in Table 5. The sum of squares is used as a measure of overall variability in the data. The value of 0.012 indicates that the variation in the experiment data is normal. Mean square values are obtained by dividing the sum of squares by the degrees of freedom. The model $F$-value of 5.07 implies the model is significant. There is only a $2.78 \%$ chance that a "Model $F$-Value" this large could occur due to noise. The importance of each term, on the dry unit weight is shown by the values in column "Prob $>F$ ". Values of "Prob $>F$ " less than 0.05 indicate model terms are significant at the $95 \%$ confidence level.

Vermiculite addition (term A) has the largest influence on the dry unit weight since the value of Prob $>F$ is the smallest for that term. The addition of PP fibers has no significant effect on the dry unit weight (the $p$ value $>0.05$ ). Further, the interaction term is not required in the model due to the higher $p$-value. The design of expert program estimates the model coefficient. Estimated coefficients are not used for interpretation of the model. Generally the model graphs are used. However these coefficients appear in the prediction equation for dry unit weight $(U W)$ :

$$
\begin{aligned}
U W\left(\mathrm{~kg} / \mathrm{m}^{3}\right) & =+0.95-0.043 \cdot A-1.0 \times 10^{-2} \cdot B+3.79 \\
& \times 10^{-3} \cdot A^{2}+3.79 \times 10^{-3} \cdot B^{2}
\end{aligned}
$$

The ANOVA tests also were done for the compressive strength and thermal conductivity data based on the quadratic model. The results for the compressive strength are given in Table 6 . The design referred to quadratic model with $R^{2}=0.96$ and standard deviation of 0.14 . As can be seen from Table 5 , the additions of vermiculite $(A)$ and polypropylene fibers $(B)$ have strong effects on the compressive strength.

The final equation in terms of coded factors for the compressive strength is:

$C S(\mathrm{MPa})=+2.81-0.66 \cdot A+0.16 \cdot B+0.03 \cdot A \cdot B$

$-0.058 \cdot A^{2}+0.062 \cdot B^{2}$

In the ANOVA results for the thermal conductivity (Table 7), the design pertains to a quadratic model with $R^{2}=0.91$ and standard deviation of 0.015 . Table 7 shows that the additives used for gypsum composite are the main effects on the thermal conductivity and the model $F$-value of 14.9 indicates the model is significant. In this case $A, B$ and $A^{2}$ are significant model terms.

The final equation in terms of coded factors for thermal conductivity $(T C)$ is

$$
\begin{aligned}
\mathrm{TC}(\mathrm{W} / \mathrm{mK}) & =+0.51-0.038 \cdot A-0.025 \cdot B+2.5 \\
& \times 10^{-3} \cdot A \cdot B-0.031 \cdot A^{2}-1.20 \times 10^{-7} \cdot B^{2}
\end{aligned}
$$

The response surfaces for models given in Eqs. (1)-(3) were constructed for all responses based on vermiculite and polypropylene fiber content (see Figs. 1-3). The effect of vermiculite and polypropylene fiber addition on the dry unit weights, compressive strength and thermal conductivity values of the gypsum composites and the optimum values for their properties are shown in Figs. 1-3, respectively.

As seen from Fig. 1, changes depend on vermiculite and fibers concentration in the mixture - as expected. Both vermiculite and fibers reduce unit weight while the effect of vermiculite is larger due to both its content in the mixture and very low density. The 
Table 4

Experimental set and results of the gypsum composites.

\begin{tabular}{|c|c|c|c|c|c|c|c|c|c|c|c|}
\hline \multirow[t]{2}{*}{ Run } & \multicolumn{2}{|c|}{ Design parameters } & \multicolumn{5}{|c|}{ Mix proportions } & \multicolumn{4}{|c|}{ All responses after 28-days } \\
\hline & Vermiculite & $\begin{array}{l}\text { Polypropylene } \\
\text { fiber }\end{array}$ & $\begin{array}{l}\text { Verm. } \\
\text { (wt.\%) }\end{array}$ & $\begin{array}{l}\text { PP fiber } \\
\text { (wt.\%) }\end{array}$ & $\begin{array}{l}\text { Gypsum } \\
\text { (wt.\%) }\end{array}$ & $\begin{array}{l}\text { Dry unit } \\
\text { weight } \\
\left(\mathrm{g} / \mathrm{cm}^{3}\right)\end{array}$ & $\begin{array}{l}\text { Porosity } \\
(\%)\end{array}$ & $\begin{array}{l}\text { Water } \\
\text { absorption } \\
(\%)\end{array}$ & $\begin{array}{l}\text { Bending } \\
\text { strength } \\
(\mathrm{MPa})\end{array}$ & $\begin{array}{l}\text { Compressive } \\
\text { strength } \\
(\mathrm{MPa})\end{array}$ & $\begin{array}{l}\text { Thermal } \\
\text { conductivity } \\
(\mathrm{W} / \mathrm{mK})\end{array}$ \\
\hline 1 & +1 & +1 & 20 & 1 & 79 & 0.89 & 40.8 & 42.8 & 1.68 & 2.32 & $0.42 \pm 0.04$ \\
\hline 2 & 0 & 0 & 10 & 0.5 & 89.5 & 0.90 & 39.2 & 43.3 & 0.88 & 2.5 & $0.50 \pm 0.05$ \\
\hline 3 & +1 & -1 & 20 & 0 & 80 & 0.92 & 40.3 & 42.6 & 1.08 & 1.98 & $0.46 \pm 0.04$ \\
\hline 4 & 0 & 0 & 10 & 0.5 & 89.5 & 0.95 & 38.5 & 40.2 & 0.9 & 2.83 & $0.50 \pm 0.04$ \\
\hline 5 & -1 & +1 & 0 & 1 & 99 & 0.99 & 36.1 & 37.4 & 0.9 & 3.56 & $0.50 \pm 0.05$ \\
\hline 6 & +1 & 0 & 20 & 0.5 & 79.5 & 0.92 & 41 & 43.6 & 1.11 & 2.1 & $0.44 \pm 0.04$ \\
\hline 7 & -1 & 0 & 0 & 0.5 & 99.5 & 1.00 & 35.6 & 37.7 & 0.85 & 3.44 & $0.50 \pm 0.03$ \\
\hline 8 & 0 & 0 & 10 & 0.5 & 89.5 & 0.96 & 36.8 & 38.4 & 1 & 2.92 & $0.53 \pm 0.02$ \\
\hline 9 & 0 & 0 & 10 & 0.5 & 89.5 & 0.96 & 36.5 & 37.5 & 1 & 2.93 & $0.52 \pm 0.04$ \\
\hline 10 & 0 & 0 & 10 & 0.5 & 89.5 & 0.97 & 38.9 & 40.1 & 0.97 & 2.81 & $0.52 \pm 0.04$ \\
\hline 11 & -1 & -1 & 0 & 0 & 100 & 1.01 & 35.9 & 37.2 & 0.8 & 3.34 & $0.55 \pm 0.03$ \\
\hline 12 & 0 & -1 & 10 & 0 & 90 & 0.97 & 38.2 & 39.9 & 0.93 & 2.69 & $0.53 \pm 0.05$ \\
\hline 13 & 0 & +1 & 10 & 1 & 89 & 0.95 & 38.5 & 40 & 1.06 & 3.09 & $0.47 \pm 0.03$ \\
\hline
\end{tabular}

Table 5

Analysis of variance (ANOVA) for response surface quadratic model for the dry unit weights with $R^{2}=0.78$

\begin{tabular}{|c|c|c|c|c|c|c|}
\hline Source & Sum of Squares & $d f$ & Mean square & $F$ value & $p$-Value Prob $>F$ & \\
\hline Model & 0.012 & 5 & $2.399 \times 10^{-3}$ & 5.07 & 0.0278 & Significant \\
\hline A - Vermiculite (\%) & 0.011 & 1 & 0.011 & 23.81 & 0.0018 & \\
\hline B - Polypropylene fiber(\%) & $6.0 \times 10^{-4}$ & 1 & $6.0 \times 10^{-4}$ & 1.27 & 0.2973 & \\
\hline $\mathrm{AB}$ & $-1.735 \times 10^{-18}$ & 1 & $-1.735 \times 10^{-18}$ & $-3.66 \times 10^{-15}$ & 1.0000 & \\
\hline$A^{2}$ & $3.974 \times 10^{-5}$ & 1 & $3.974 \times 10^{-5}$ & 0.084 & 0.7804 & \\
\hline $\mathrm{B}^{2}$ & $3.974 \times 10^{-5}$ & 1 & $3.974 \times 10^{-5}$ & 0.084 & 0.7804 & \\
\hline Residual & $3.313 \times 10^{-3}$ & 7 & $4.732 \times 10^{-4}$ & & & \\
\hline Lack of fit & $2.326 \times 10^{-4}$ & 3 & $7.755 \times 10^{-5}$ & 0.10 & 0.9554 & Not significant \\
\hline Pure error & $3.08 \times 10^{-3}$ & 4 & $7.70 \times 10^{-4}$ & & & \\
\hline Cor total & 0.015 & 12 & & & & \\
\hline
\end{tabular}

Table 6

Analysis of variance (ANOVA) for response surface quadratic model for the compressive strengths with $R^{2}=0.96$.

\begin{tabular}{|c|c|c|c|c|c|c|}
\hline Source & Sum of squares & $d f$ & Mean square & $F$ value & $p$-Value Prob $>F$ & \\
\hline Model & 2.76 & 5 & 0.55 & 29.65 & 0.0001 & Significant \\
\hline A - Vermiculite (\%) & 2.59 & 1 & 2.59 & 139.03 & $<0.0001$ & \\
\hline B - Polypropylene fiber(\%) & 0.15 & 1 & 0.15 & 8.25 & 0.0239 & \\
\hline $\mathrm{AB}$ & $3.600 \times 10^{-3}$ & 1 & $3.600 \times 10^{-3}$ & 0.19 & 0.6733 & \\
\hline A2 & $9.269 \times 10^{-3}$ & 1 & $9.269 \times 10^{-3}$ & 0.5 & 0.5031 & \\
\hline B2 & 0.011 & 1 & 0.011 & 0.57 & 0.4742 & \\
\hline Residual & 0.13 & 7 & 0.019 & & & \\
\hline Lack of fit & $7.984 \times 10^{-3}$ & 3 & $2.661 \times 10^{-3}$ & 0.087 & 0.9635 & Not significant \\
\hline Pure error & 0.12 & 4 & 0.031 & & & \\
\hline Cor total & 2.89 & 12 & & & & \\
\hline
\end{tabular}

lowest unit weight was observed as $0.89 \mathrm{~g} / \mathrm{cm}^{3}$ in the mixture containing $20 \%$ vermiculite and $1.0 \%$ fiber. The highest unit weight belongs to neat gypsum.

As seen from Fig. 2, compressive strength of our composites varies between $3.56 \mathrm{MPa}$ and $1.98 \mathrm{MPa}$. The lowest value appears in Run 3. Vermiculite reduces compressive strength of composites. The reason behind it is that expanded vermiculite, which is used in this study, is not a load carrying mineral. Also, vermiculite increases porosity. The more porosity, the more compressive strength loss. On the other hand, fibers added into mixture slightly enhance the compressive strength.

As seen in Fig. 3, thermal conductivity decreases as a function of both vermiculite and PP fibers contents. Density decreases with increasing expanded vermiculite content in the mix. Thermal

Table 7

Analysis of variance (ANOVA) for response surface quadratic model for the thermal conductivities with $R^{2}=0.91$.

\begin{tabular}{|c|c|c|c|c|c|c|}
\hline Source & Sum of squares & $d f$ & Mean square & $F$ value & $p$-Value Prob $>F$ & \\
\hline Model & 0.016 & 5 & $3.167 \times 10^{-3}$ & 14.9 & 0.0013 & Significant \\
\hline A - Vermiculite (\%) & $8.817 \times 10^{-3}$ & 1 & $8.817 \times 10^{-3}$ & 41.49 & 0.0004 & \\
\hline B - Polypropylene fiber(\%) & $3.750 \times 10^{-3}$ & 1 & $3.750 \times 10^{-3}$ & 17.65 & 0.0040 & \\
\hline $\mathrm{AB}$ & $2.500 \times 10^{-5}$ & 1 & $2.500 \times 10^{-5}$ & 0.12 & 0.7417 & \\
\hline$A^{2}$ & $2.690 \times 10^{-3}$ & 1 & $2.690 \times 10^{-3}$ & 12.66 & 0.0092 & \\
\hline $\mathrm{B}^{2}$ & $4.023 \times 0^{-6}$ & 1 & $4.023 \times 10^{-6}$ & 0.019 & 0.8944 & \\
\hline Residual & $1.488 \times 10^{-3}$ & 7 & $2.125 \times 10^{-4}$ & & & \\
\hline Lack of fit & $7.676 \times 10^{-4}$ & 3 & $2.559 \times 10^{-4}$ & 1.42 & 0.3602 & Not significant \\
\hline Pure error & $7.200 \times 10^{-4}$ & 4 & $1.800 \times 10^{-4}$ & & & \\
\hline Cor total & 0.018 & 12 & & & & \\
\hline
\end{tabular}




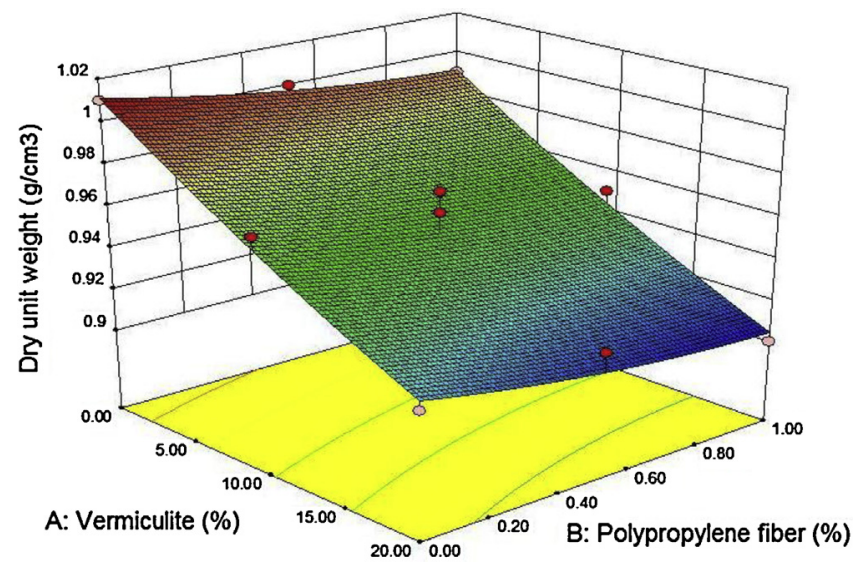

Fig. 1. Response surfaces for the model given in Eq. (1) for the dry unit.

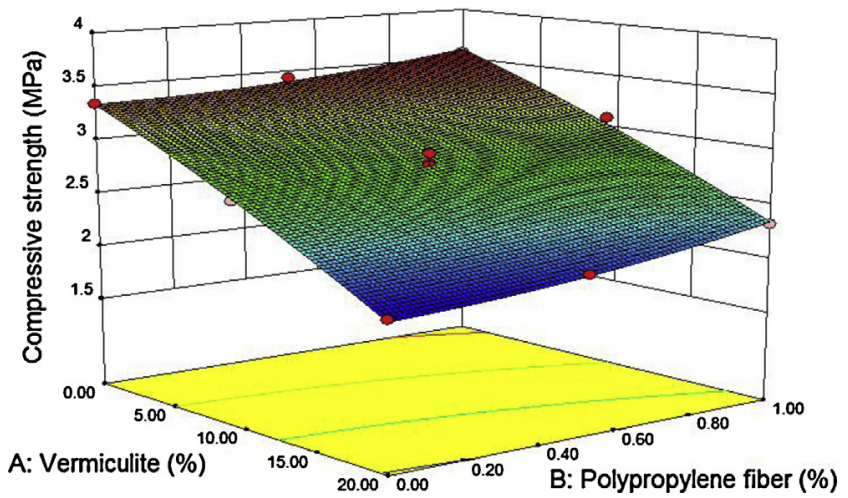

Fig. 2. Response surfaces for model given in Eq. (2) for the compressive strength.

conductivity decreases due to the decrease of density. Also, vermiculite increased porosity of our composites.

\section{Numerical modeling}

\subsection{Mathematical model of gypsum composite}

In order to evaluate the structural load capacity of the three-point bending gypsum composite, we have employed a mathematical model of concrete based on Willam and Warnke $[29,41,42]$ for stresses, so that the model predicts both material failure modes: cracking and crushing.

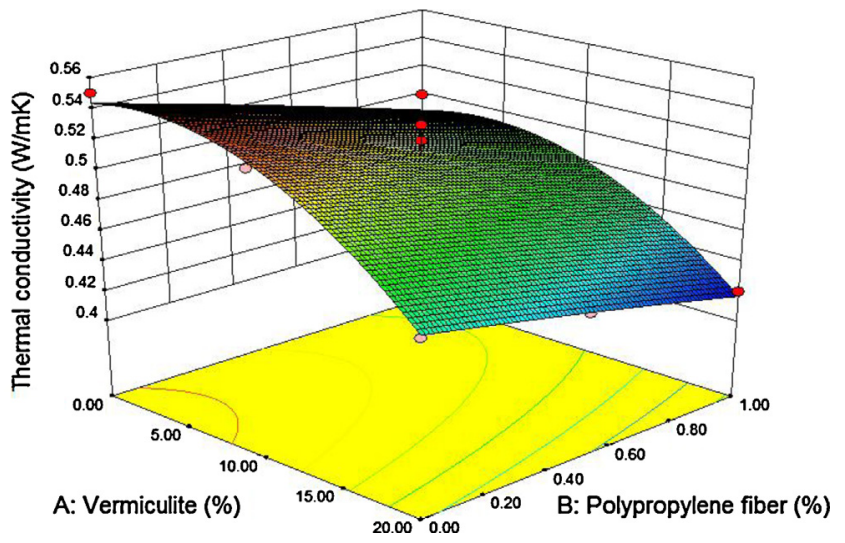

Fig. 3. Response surfaces for model given in Eq. (3) for the thermal conductivity.

\subsection{Material properties}

The main properties of the composite gypsum used in the numerical model are obtained from our laboratory tests and earlier work $[28,29,41,42]$ :

- Linear properties:

- Density: according to the experimental results and Eq. (1) with $\mathrm{kg} / \mathrm{m}^{3}, \rho=U W$

Poisson's ratio: 0.18

- Nonlinear properties for William and Warnke model:

- Ultimate uniaxial compressive strength, according to the experimental results and Eq. (2) in MPa: $f_{c}=C S$.

。 Ultimate uniaxial tensile strength, $f_{t}=0.21 \times \sqrt[3]{f_{c}^{2}}=0.21 \times$ $\sqrt[3]{C S^{2}} \mathrm{MPa}$.

- Young's modulus: $E=\frac{f_{c}}{0.63} \times 1000=\frac{C S}{0.63} \times 1000 \mathrm{MPa}$.

- Shear transfer coefficient for an open crack: 0.1.

- Shear transfer coefficient for a closed crack: 0.7.

- The PP fiber material properties (see Table 2) used in the model are introduced as rebars in local $X, Y$ and $Z$ directions (see Fig. 4(a)), with the following linear properties [43]:

- Density of fibers: $920 \mathrm{~kg} / \mathrm{m}^{3}$.

- Young's modulus: 2000-3900 MPa.

○ Poisson's ratio: 0.4

\subsection{Finite element model and boundary conditions}

The three-point bending composite gypsum specimen of $0.4 \times 0.3 \mathrm{~m}$ (see Fig. $4 \mathrm{a}$ ) has been modeled by means of solid type tetrahedral finite elements named SOLID65 (see Fig. 4b) [44,45]. Such a finite element is appropriate to reproduce the non-linear structural behavior of fragile materials such as concrete or gypsum; that is to say, the failure modes of cracking and crushing. There are eight nodes with three degrees of freedom per node: translations in $X, Y$ and $Z$ directions. We have considered in this finite element the extra displacement shapes and we have included tensile stress relaxation after cracking in order to help convergence.

A fine mesh, with a meshing parameter of $2 \times 10^{-3} \mathrm{~m}$, has been used, giving place to a FEM model composed of 62,118 nodes and 50,500 elements (see Fig. 4c), with an excellent Jacobian ratio and element quality.

On the one hand, a ramped displacement ranging from $1.2 \times 10^{-4}$ to $1.6 \times 10^{-4} \mathrm{~m}$ is applied to the central line of the specimen. On the other hand, the displacements in $X$ direction have been constrained on both lateral supports (see Fig. 4d).

\subsection{FEM analysis and results}

In order to solve the mathematical model of this problem, we have taking into account the following assumptions for the nonlinear FEM analysis:

- Newton-Raphson integration scheme.

- Ramped loading: the applied central displacement is linearly interpolated for each substep from the value of the previous load step to the value of this load step.

- Maximum number of iterations per load increment: 25.

- Force convergence parameter: a tolerance of $0.5 \%$ with respect to the $L^{2}$ Euclidean norm, with a minimum value of $0.01 \mathrm{~N}$.

- Analysis time steps:

o Initial time step: 0.01 .

- Minimum time step: 0.0005 .

○ Maximum time step: 0.05 . 


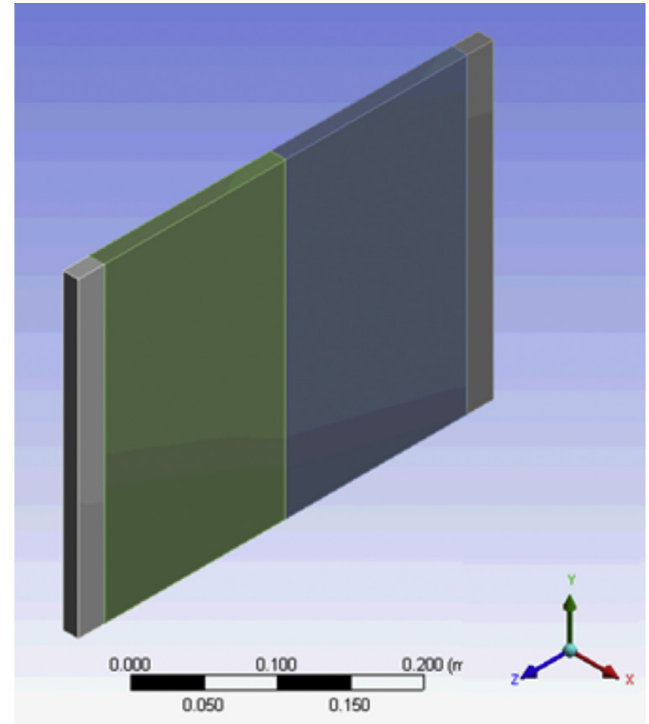

(a)

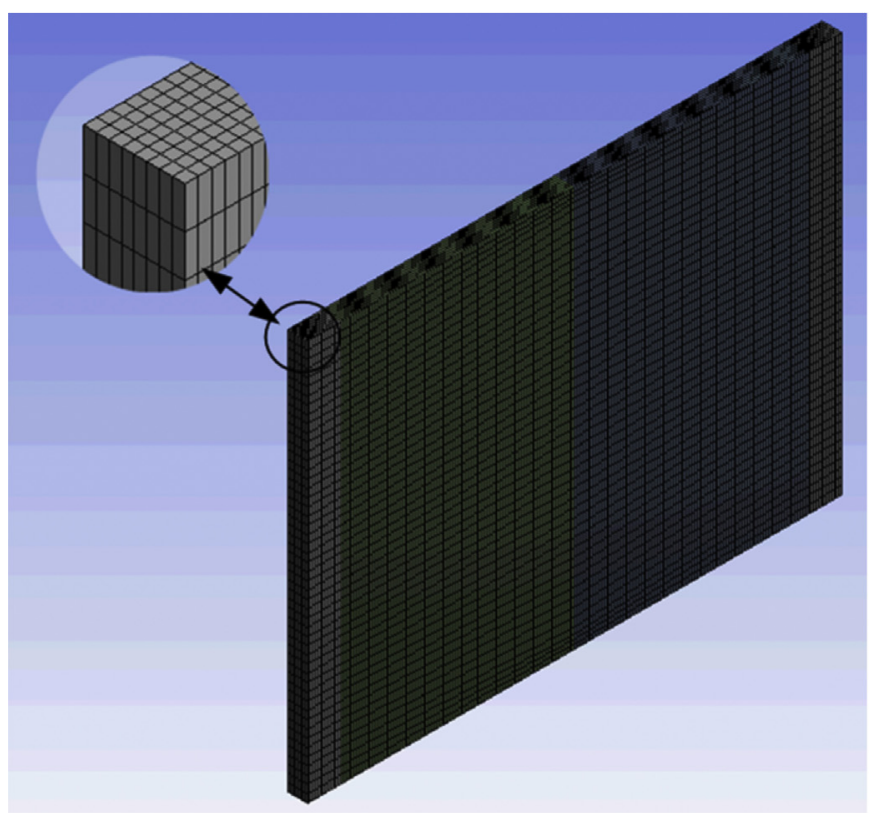

(c)

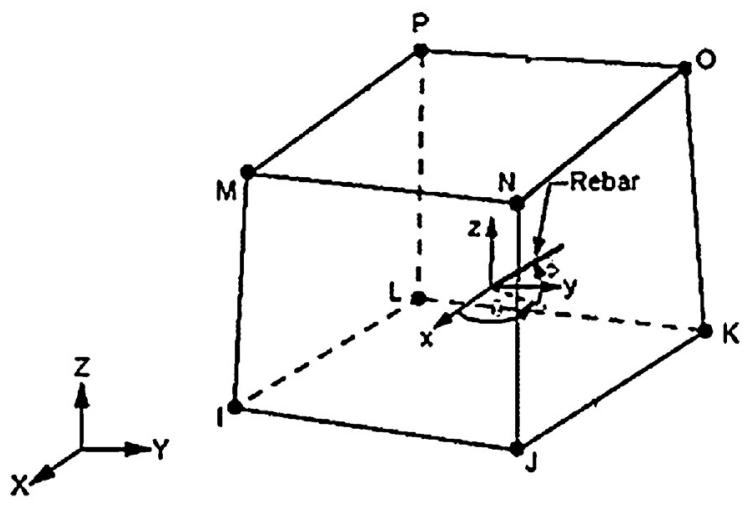

(b)

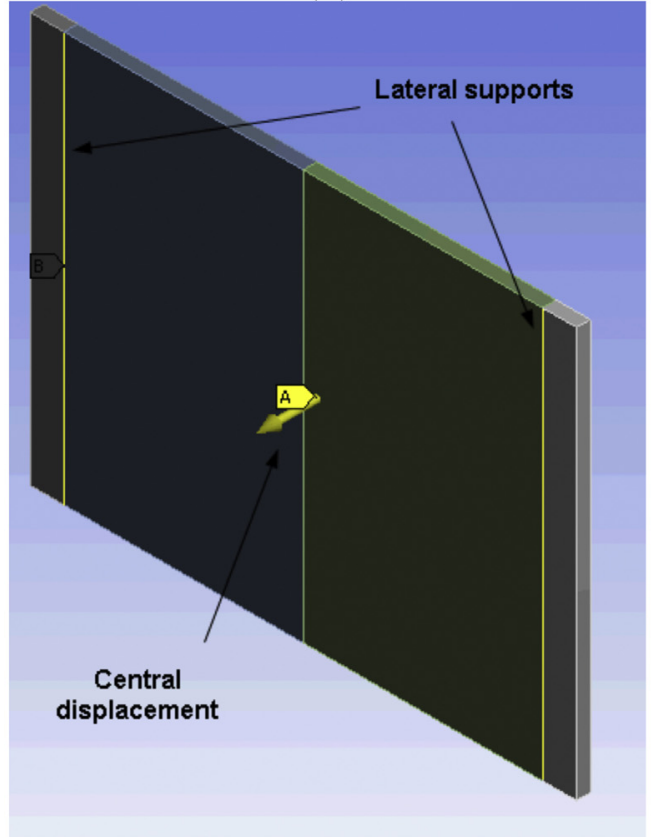

(d)

Fig. 4. FEM model: (a) finite element SOLID 65, (b) geometrical model, (c) FEM mesh and a detail and (d) boundary conditions.

The problem was solved in a workstation computer with a CPU Xeon 64 bits, 64 GB RAM memory, 5 TB hard disk and four cores. The total elapsed average CPU time per FEM model and each nonlinear structural analysis was $20,000 \mathrm{~s}$ and the total number of iterations in order to get the convergence about 230. For the DOE analysis, 25 different FEM models per gypsum specimen were built and the total CPU time was about 400,000 s.

From the FEM results shown in Fig. 5, we see that:

- The specimen deformation follows the typical structural behavior of a three point bending test with a plastic hinge in the central part, as seen in Fig. 5 a.

- Maximum principal stresses show clearly the cracking material failure in the central part of the specimen (see Fig. 5b).

- Normal stress values are show in Fig. 5c: two vertical bands in the central part of the cracking specimen, due to the presence of PP fibers in the gypsum composite.
- The safety factor of the specimen is shown in Fig. 5d, in which it is possible to see the wide band of material near cracking-point failure as well as the central plastic hinge.

- Finally, Fig. 5e shows the force-displacement diagram including the cracking or suddenly failure point and the subsequent residual resistance.

\section{Design of experiments analysis and optimization}

The design of experiments (DOE) methodology is a useful complement to multivariate data analysis because it generates "structured" data tables that contain an important amount of structured variation $[23,27,28]$. This mathematical structure is used as a basis for multivariate modeling, what guarantees stable and robust numerical models. Careful sample selection increases the chances of extracting useful information from the data tables. The critical part is to decide which input variables or parameters to change, 


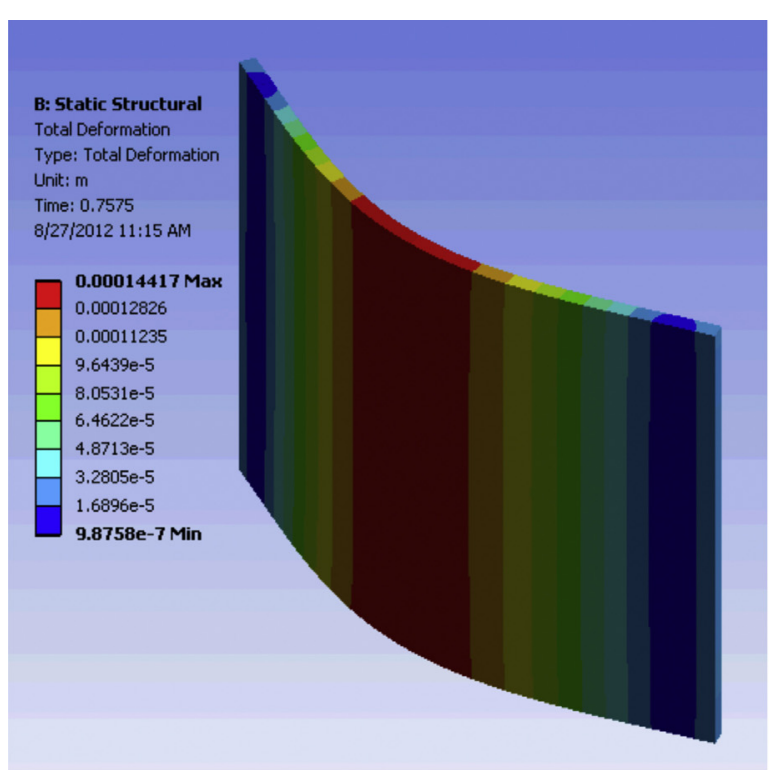

(a)

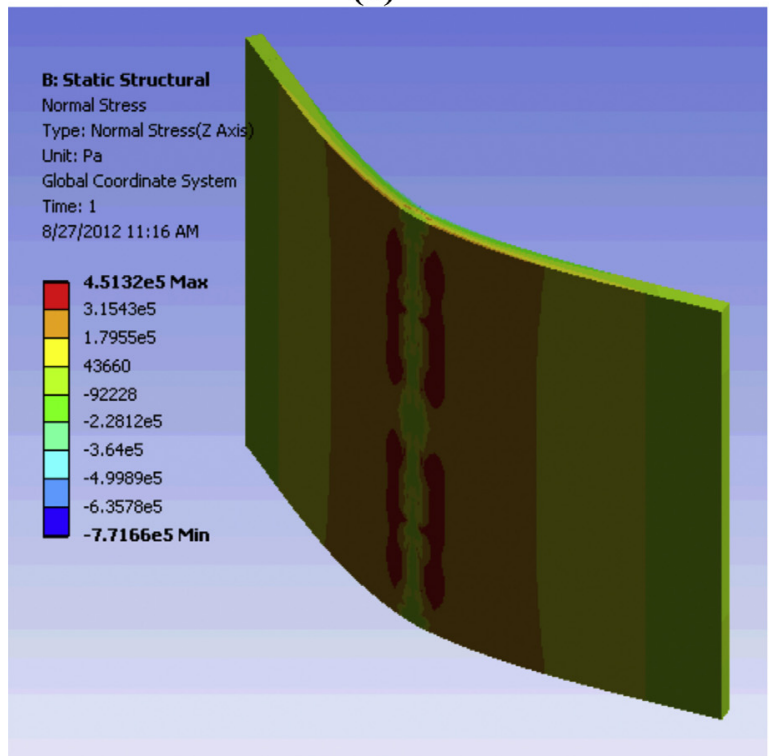

(c)

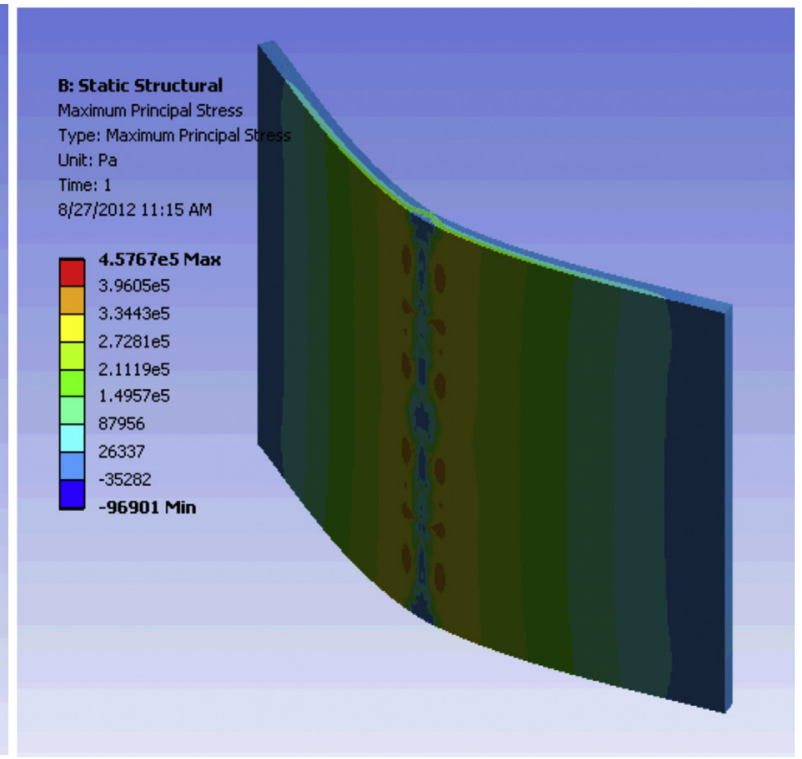

(b)

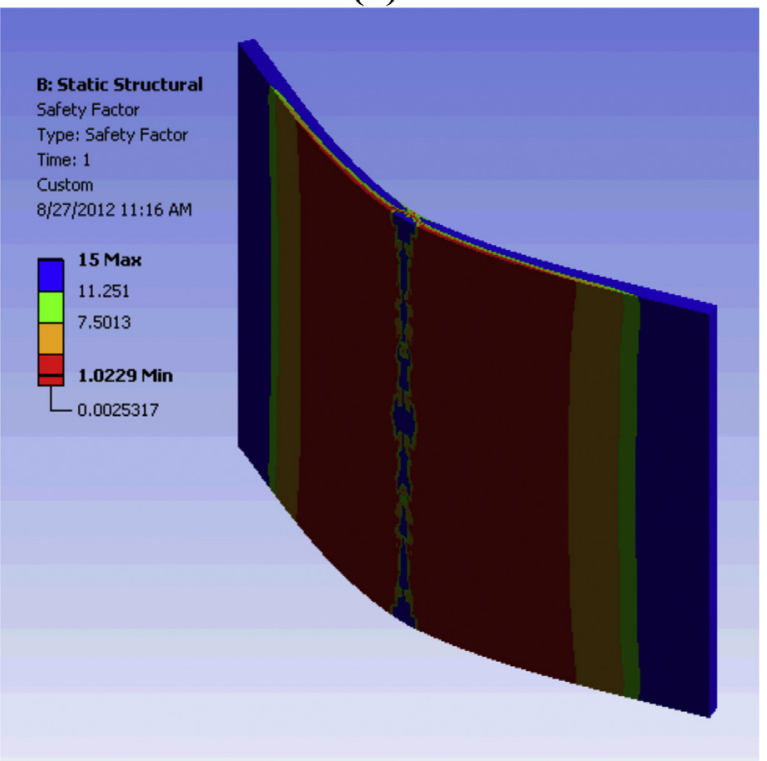

(d)

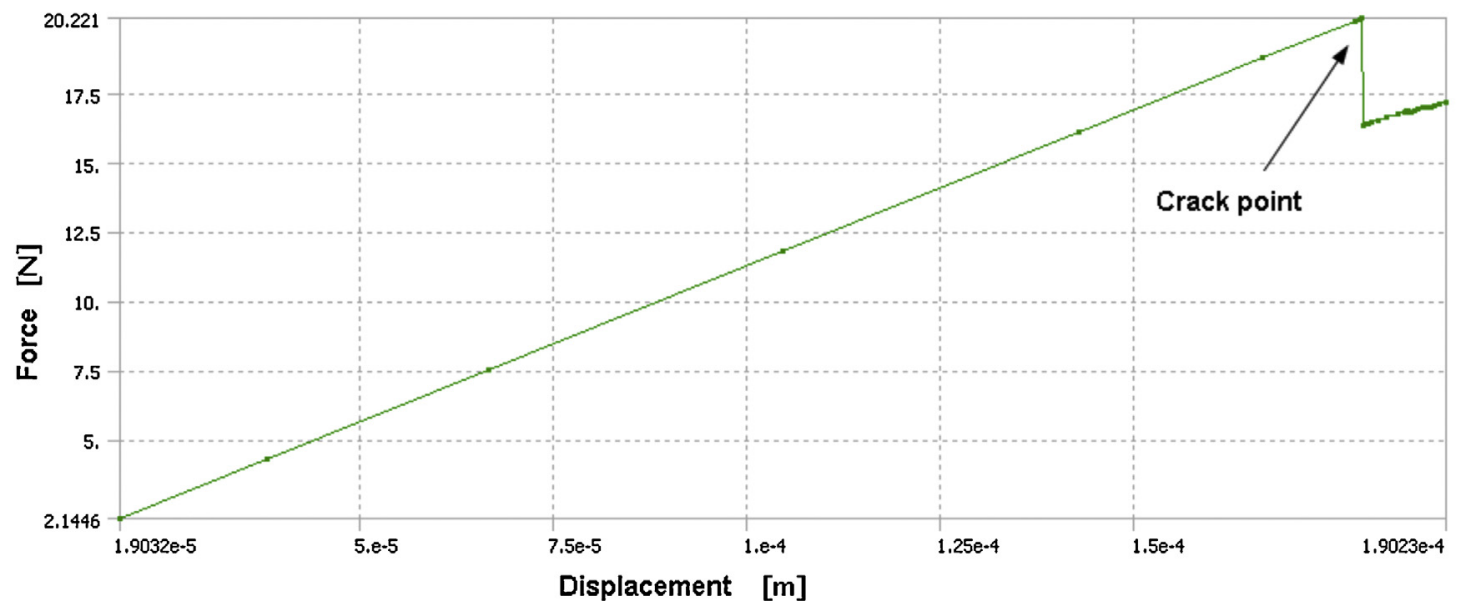

Fig. 5. FEM results: (a) maximum displacement (m), (b) maximum principal stress (Pa), (c) normal stress (Pa), (d) safety factor and (e) force-displacement graph. 


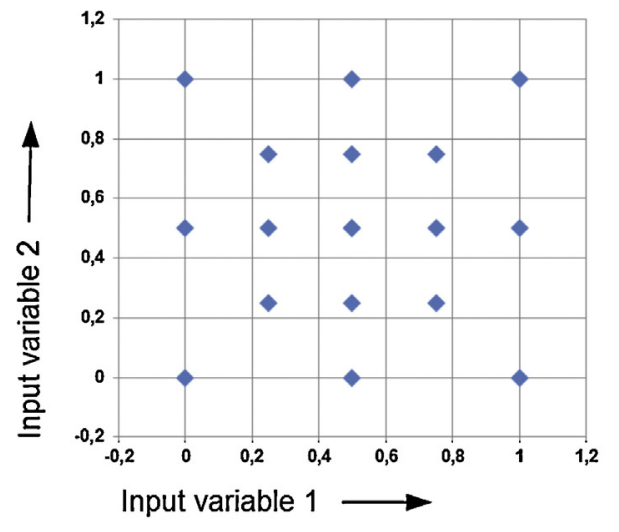

(a)

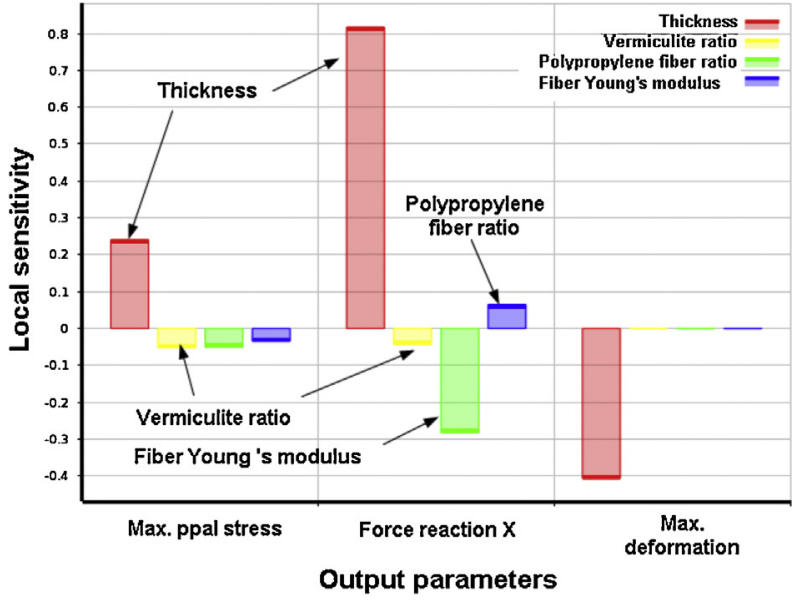

(b)

Fig. 6. DOE analysis: (a) explicit points distribution in the case of CCD with an enhanced face-centered scheme and (b) sensitivity analysis.

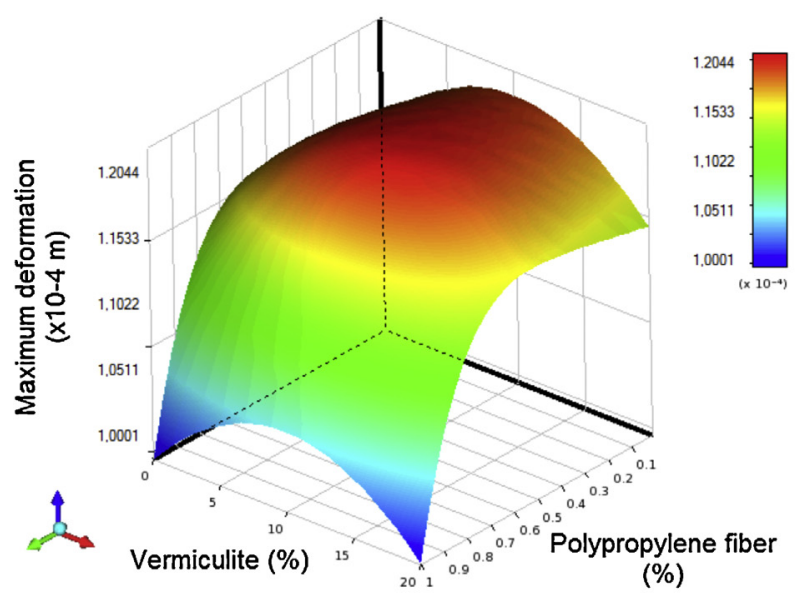

(a)

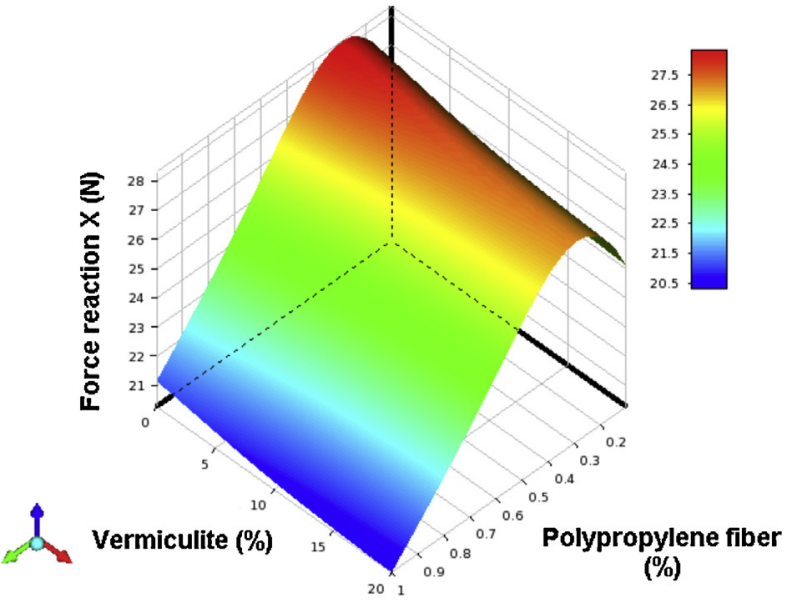

(b)

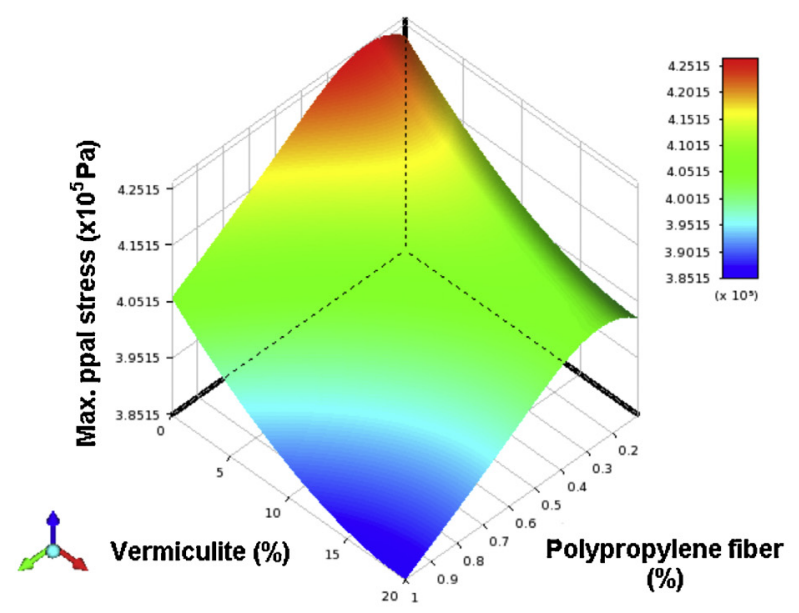

(c)

Fig. 7. DOE results: (a) maximum deformation versus vermiculite and polypropylene ratios, (b) maximum reaction versus vermiculite and polypropylene ratios, and (c) maximum principal stress versus vermiculite and polypropylene ratios. 
the intervals for this variation, and the pattern of the experimental points (DOE type).

A DOE analysis has been carried out in order to analyze effects of the vermiculite and polypropylene ratios on the strength of the composites. We have selected a pattern based on a central composite design (CDD) with an enhanced face-centered scheme (see Fig. 6a). As input parameters, the following variables have been considered:

- Specimen thickness, with an initial value of $12 \mathrm{~mm}$, ranging from 10 to $15 \mathrm{~mm}$.

- Vermiculite ratio as percentage, with an initial value of $10 \%$ and ranging from $0 \%$ to $20 \%$

- Polypropylene fiber ratio in percentage, with an initial value of $0.5 \%$, ranging from $0.01 \%$ to $1 \%$.

- Elastic modulus of polypropylene, with an initial value of $3000 \mathrm{MPa}$, ranging from 2000 to $3900 \mathrm{MPa}$.

As output parameters we have the maximum principal stress, the force reaction in the $\mathrm{Y}$ direction and the maximum displacement. A total of seventeen different FEM models for each three-point bending specimen have been calculated. The surface response and the sensitivity analysis were obtained.

First, the sensitivity analysis shows the influence of the input parameters with respect to the output parameters (see Fig. 6b). The most important input variable corresponds to the specimen thickness, followed by the vermiculite ratio in case of maximum principal stress output parameter, and finally, the polypropylene fiber ratio.

The DOE analysis leads to the following findings:

- Fig. 7a shows the variation of the maximum deformation of the three point bending specimen as a function of the vermiculite and polypropylene fiber ratios. With increasing the addition of polypropylene fibers, the maximum deformation decreases.

- Fig. 7b shows the evolution of the maximum force reaction as a function of the vermiculite and polypropylene fiber ratios. The vermiculite addition decreases the maximum reaction in the specimen; the polypropylene fiber ratio increases the plasticity of the gypsum composite.

- Finally, Fig. 7c shows the variation of the maximum principal stress as a function of the vermiculite and polypropylene fiber ratios. In this case, the addition of both vermiculite and polypropylene fiber decreases the maximum principal stress, due to the elasto-plastic behavior of the gypsum composite.

Finally, from the above response surfaces (Fig. 7), it is possible to obtain the optimum values of the vermiculite and polypropylene fiber ratios in order to obtain the best strength of the gypsum composite. For this purpose, a response surface optimization (RSO) is carried out [46], and the closest solution to the objective function is found. The numerical RSO procedure is a constrained, multi-objective optimization technique in which the "best" possible designs are obtained from a thousand samples set given the objectives to look for.

We have built the objective function with the following constraints:

- Maximize reaction force $F X ; F X \geq 28 \mathrm{~N}$ (default importance).

- Minimize vermiculite ratio, $A$ (default importance).

- Minimize polypropylene fiber ratio, $B$ (default importance).

The optimum material properties obtained from the above RSO analysis are shown in Table 8.
Table 8

Optimization based on DOE analysis.

\begin{tabular}{lllll}
\hline & Thickness $(\mathrm{mm})$ & $A(\%)$ & $B(\%)$ & $F X(N)$ \\
\hline Candidate point 1 & 12.88 & 0.19 & 0.14 & 28.64 \\
Candidate point 2 & 14.32 & 0.54 & 0.13 & 36.34 \\
Candidate point 3 & 15.00 & 0 & 0.10 & 38.51 \\
\hline
\end{tabular}

In summary, the optimum and economically acceptable values of the vermiculite and polypropylene fiber ratios in order to obtain the best strength of the gypsum composite are the following:

- Vermiculite/gypsum ratio by weight: $0-0.54 \%$.

- Polypropylene/gypsum ratio by weight: $0.1-0.14 \%$.

\section{Conclusions}

As expected, the unit weights of gypsum composites depend on vermiculite and fibers concentration in the mixture. Vermiculite reduces the compressive strength while PP fibers somewhat enhance the strength. The thermal conductivity of our composites decreases with increasing vermiculite content.

The finite element method (FEM) has been shown as suitable tool in the modeling and analysis of complex nonlinear gypsum composites. A three point bending specimen FEM model with a William-Warnke concrete-rebar constitutive model has been developed to study gypsum composites with success. That model is able to reproduce the structural behavior of the gypsum composites with a high degree of accuracy, taking into account the cracking and crushing phenomena and showing clearly the plastic hinge and loss of resistance in case of failure.

The parametric study with the help of the DOE allows identification of the most relevant input parameters of the process in order to determine their influence in the structural load capacity of the three point bending specimen made up gypsum composite. Furthermore, the DOE also provides more information than other traditional experimental methods, because it allows an assessment on the significance of not only input variables acting alone, but also factors acting in combination with one another.

A mathematical model has been developed to study and optimize the fiber ratio of gypsum composites. This methodology will benefit the construction products based on structural principles.

One notes that there are two forms of polypropylene, in function of the nucleation procedure used [47]. In concretes PP fibers have been used before, irradiated with gamma radiation or otherwise [48]. Steel fibers have been used before also [49], but then objectives of the present work of providing low density and low thermal conductivity would be missed. Finally, we note that construction materials based on polymeric rather than mineral matrices are in use also [50].

\section{Acknowledgements}

The authors wish to acknowledge the experimental results and financial support provided by the GICONSIME Research Team in the University of Oviedo and the Bartin University. The authors acknowledge the partial funding from the Gijon City Council through the SV-13-GIJON-1.7 project and the financial support provided by the FICYT and the Spanish Ministry of Science and Innovation through the research projects co-financed with FEDER funds: FC-10-EQUIP10-17 and BIA2012-31609.We also thank Swanson Analysis Inc. for the use of ANSYS v12 University Research program. 


\section{References}

[1] S. Eve, M. Gomina, A. Gmouh, A. Samdi, R. Moussa, G. Orange, Microstructural and mechanical behaviour of polyamide fibre-reinforced plaster composites, Journal of European Ceramic Society 22 (2002) 2269-2275.

[2] A. Colak, Physical and mechanical properties of polymer-plaster composites, Materials Letters 60 (2006) 1977-1982.

[3] S. Gutiérrez-Gonzalez, J. Gadea, A. Rodríguez, M.T. Blanco-Varela, V. Calderon, Compatibility between gypsum and polyamide powder waste to produce lightweight plaster with enhanced thermal properties, Construction and Building Materials 34 (2012) 179-185

[4] S. Gutierrez-Gonzalez, J. Gadea, A. Rodriguez, C. Junco, V. Calderon, Lightweight plaster materials with enhanced thermal properties made with polyurethane foam wastes, Construction and Building Materials 28 (2012) 653-658.

[5] M.H.P. Gazineu, V.A. Dos Santos, C.A. Hazin, W.E. de Vasconcelos, C.C. Dantas, Production of polymer-plaster composite by gamma irradiation, Progress in Nuclear Energy 53 (2011) 1140-1144.

[6] M. Murat, A. Attari, Modification of some physical properties of gypsum plaster by addition of clay minerals, Cement and Concrete Research 2 (1991)378-387.

[7] A. Vimmrova, M. Keppert, L. Svoboda, R. Cerny, Lightweight gypsum composites: design strategies for multi-functionality, Cement and Concrete Composites 33 (2011) 84-89.

[8] M.S. Baspınar, E. Kahraman, Modifications in the properties of gypsum construction element via addition of expanded macroporous silica granules, Construction and Building Materials 25 (2011) 3327-3333.

[9] T. Toppi, L. Mazzarella, Gypsum based composite materials with microencapsulated PCM: experimental correlations for thermal properties estimation on the basis of the composition, Energy and Buildings 57 (2013) 227-236.

[10] C.M. Lai, R.H. Chen, C.Y. Lin, Heat transfer and thermal storage behaviour of gypsum boards incorporating microencapsulated PCM, Energy and Buildings 42 (2010) 1259-1266.

[11] D. Heim, J.A. Clarke, Numerical modelling and thermal simulation of PCM-gypsum composites with ESP-r, Energy and Buildings 36 (2004) 795-805.

[12] A. Oliver, Thermal characterization of gypsum boards with PCM included: thermal energy storage in buildings through latent heat, Energy and Buildings 48 (2012) 1-7.

[13] M. Li, Z. Wu, M. Chen, Preparation and properties of gypsum-based heat storage and preservation material, Energy and Buildings 43 (2011) 2314-2319.

[14] A. Sarı, A. Bicer, Preparation and thermal energy storage properties of building material-based composites as novel form-stable PCMs, Energy and Buildings 51 (2012) 73-83.

[15] Q.L. Yu, H.J.H. Brouwers, Development of a self-compacting gypsumbased lightweight composite, Cement and Concrete Composites 34 (2012) 1033-1043.

[16] H.A. West, A.F. Sprecher, Fiber reinforced composite materials, Journal of Materials Education 13 (1991) 161-172.

[17] O. Gencel, C. Ozel, W. Brostow, G. Martinez-Barrera, Mechanical properties of self-compacting concrete reinforced with polypropylene fibers, Materials Research Innovations 15 (2011) 216-225.

[18] J.A. Mohandesi, A. Sangghaleh, A. Nazari, N. Pourjavad, Analytical modeling of strength in randomly oriented PP and PPTA short fiber reinforced gypsum composites, Computational Materials Science 50 (2011) 1619-1624.

[19] E. Tazawa, Effect of self stress on flexural strength of gypsum-polymer composites, Advanced Cement-Based Materials 7 (1998) 1-7.

[20] Y.F. Wu, The effect of longitudinal reinforcement on the cyclic shear behavior of glass fiber reinforced gypsum wall panels: tests, Engineering Structures 26 (2004) 1633-1646.

[21] O. Gencel, F. Koksal, M. Sahin, M.Y. Durgun, H.E. Hagg Lobland, W. Brostow, Modeling of thermal conductivity of concrete with vermiculite by using artificial neural networks approaches, Experimental Heat Transfer 26 (2013) 360-383.

[22] F. Koksal, O. Gencel, W. Brostow, H.E. Hagg-Lobland, Effect of high temperature on mechanical and physical properties of lightweight cement based refractory including expanded vermiculite, Materials Research Innovations 16(2012) 7-13.

[23] D.C. Montgomery, Design and Analysis of Experiments, John Wiley \& Sons, New York, 1997.

[24] J.J. del Coz Díaz, P.J. García Nieto, J. Domínguez Hernández, A. Suárez Sánchez, Thermal design optimization of lightweight concrete blocks for internal oneway spanning slabs floors by FEM, Energy and Buildings 41 (12) (2009) 1276-1287.
[25] O. Gencel, C. Ozel, F. Koksal, G. Martinez-Barrera, W. Brostow, H. Polat, Fuzzy logic model for prediction of properties of fiber-reinforced self-compacting concrete, Materials Science Medziagotyra 19 (2013) 203-215.

[26] J.J. Del Coz Diaz, P.J. García Nieto, A.L. Martínez-Luengas, J.L. Suárez Sierra, A study of the collapse of a WWII communications antenna using numerical simulations based on design of experiments by FEM, Engineering Structures 32 (2010) 1792-1800.

[27] G.B. Smith, J.L.C. Aguilar, A.R. Gentle, D. Chen, Multi-parameter sensitivity analysis: a design methodology applied to energy efficiency in temperate climate houses, Energy and Buildings 55 (2012) 668-673.

[28] J.J. Del Coz Diaz, P.J. Garcia Nieto, F.P. Alvarez Rabanal, A.L. Martínez-Luengas, Design and shape optimization of a new type of hollow concrete masonry block using the finite element, Engineering Structures 33 (2011) 1-9.

[29] P. Mehta, P. Monteiro, Concrete: Microstructure, Properties and Materials, McGraw-Hill, New York, 2005.

[30] A. Colak, Density and strength characteristics of foamed gypsum, Cement and Concrete Composites 22 (2000) 193-200.

[31] M. Arikan, K. Sobolev, The optimization of a gypsum-based composite material, Cement and Concrete Research 32 (2002) 1725-1728.

[32] TS EN 13279-1, Gypsum Binders and Gypsum Plasters - Part 1: Definitions and Requirements, Ankara, 2009.

[33] G.E. Box, N.R. Draper, Empirical Model Building and Response Surfaces, John Wiley \& Sons, New York, 1987.

[34] R.H. Myers, D.C. Montgomery, Response Surface Methodology: Process and Product Optimization Using Design Experiments, John Wiley \& Sons, New York, 1995.

[35] M.J. Simon, E.S. Lagergren, L.G. Wathne, Optimising high performance concrete mixtures using statistical response surface methods, in: Proceedings 5th International Symposium of the Norwegian Concrete Association on Utilization of High Strength/High Performance Concrete, Norwegian Concrete Association, Sandefjord, Norway, 1999 June, pp. 1311-1321.

[36] F. Bayramov, C. Tasdemir, M.A. Tasdemir, Optimisation of steel fiber reinforced concretes by means of statistical response surface method, Cement and Concrete Research 26 (2004) 665-675.

[37] O. Gencel, F. Koksal, W. Brostow, Wear minimisation in concrete with haematite, Materials Research Innovations 17 (2013) 92-97.

[38] TS EN 13279-2, Gypsum Binders and Gypsum Plasters - Part 2: Test Methods, Ankara, 2009.

[39] J. Cha, J. Seo, S. Kim, Building materials thermal conductivity measurement and correlation with heat flow meter, laser flash analysis and TCi, Journal of Thermal Analysis and Calorimetry 109 (1) (2012) 295-300.

[40] D. Mikulić, B. Milovanović, I. Gabrijel, Analysis of thermal properties of cement paste during setting and hardening Nondestructive Testing of Materials and Structures (RILEM Bookseries), vol. 6, Springer, Netherlands, 2013, pp. $465-471$

[41] P. Fuschi, M. Dutko, D. Peric, D.R.J. Owen, On numerical integration of the five-parameter model for concrete, Computers and Structures 53 (1994) $825-838$.

[42] K.J. Willam, E.D. Warnke, Constitutive model for the triaxial behaviour of concrete, in: Proceedings of the International Association for Bridge and Structural Engineering, 19, Bergamo, Italy, 1975, pp. 174-178.

[43] N.P. Inglea, M.W. Kinga, M.A. Zikryd, Finite element analysis of barbed sutures in skin and tendon tissues, Journal of Biomechanics 43 (2010) 879-886.

[44] S. Moaveni, Finite Element Analysis: Theory and Application with ANSYS, Prentice Hall, New York, 2007.

[45] E. Madenci, I. Guven, The Finite Element Method and Applications in Engineering Using ANSYS, Springer-Verlag, Berlin, 2007.

[46] J. Antony, Design of Experiments for Engineers and Scientists, ButterworthHeinemann, New York, 2003.

[47] A. Romankiewicz, T. Sterzynski, W. Brostow, Structural characterization of $\alpha$ - and $\beta$-nucleated isotactic polypropylene, Polymer International 53 (2004) 2086-2091.

[48] G. Martinez-Barrera, E. Vigueras-Santiago, S. Hernandez-Lopez, C. MenchacaCampos, W. Brostow, Mechanical improvement of concrete by irradiated polypropylene fibers, Polymer Engineering and Science 45 (2005) 1426-1431.

[49] O. Gencel, W. Brostow, T. Datashvili, M. Thedford, Workability and mechanica performance of steel fiber-reinforced self-compacting concrete with fly ash, Composite Interfaces 18 (2011) 169-184.

[50] G. Martinez-Barrera, E. Vigueras-Santiago, O. Gencel, H.E. Hagg-Lobland, Polymer concretes: a description and methods for modification and improvement, Journal of Materials Education 33 (2011) 37-52. 